\title{
Wearable and washable conductors for active textiles
}

\section{Citation}

Le Floch, Paul, Xi Yao, Qihan Liu, Zhengjin Wang, Guodong Nian, Yu Sun, Li Jia, and Zhigang Suo. 2017. "Wearable and Washable Conductors for Active Textiles." ACS Applied Materials \& Interfaces (July 11). doi:10.1021/acsami.7b07361.

\section{Published Version}

10.1021/acsami.7b07361

\section{Permanent link}

http://nrs.harvard.edu/urn-3:HUL.InstRepos:33840772

\section{Terms of Use}

This article was downloaded from Harvard University's DASH repository, and is made available under the terms and conditions applicable to Open Access Policy Articles, as set forth at http:// nrs.harvard.edu/urn-3:HUL.InstRepos:dash.current.terms-of-use\#OAP

\section{Share Your Story}

The Harvard community has made this article openly available.

Please share how this access benefits you. Submit a story.

Accessibility 


\section{Wearable and washable conductors for active}

\section{textiles}

Paul Le Floch ${ }^{l}$, Xi Yao ${ }^{l}$, Qihan Liu ${ }^{l}$, Zhengjing Wang ${ }^{l}$, Guodong Nian ${ }^{l}$, Yu Sun ${ }^{2}$, Li Jia ${ }^{2}$, Zhigang Suo ${ }^{1 *}$

${ }^{1}$ School of Engineering and Applied Sciences, Kavli Institute for Bionano Science and Technology, Harvard University, MA 02138

${ }^{2}$ Department of Polymer Science, The University of Akron, Akron, Ohio 44325-3909

*Corresponding author: suo@ seas.harvard.edu

KEYWORDS: Ionic conductor, hydrogel, elastomer, water-permeability, hygroscopic effect, wearable, washable, active textile

ABSTRACT: The emergence of stretchable electronics and its potential integration with textiles have highlighted a challenge: textiles are wearable and washable, but electronic devices are not. Many stretchable conductors have been developed to enable wearable active textiles, but little has been done to make them washable. Here we demonstrate a new class of stretchable conductors that can endure wearing and washing conditions commonly associated with textiles. Such a conductor consists of a hydrogel, a dissolved hygroscopic salt, and a butyl rubber coating. The hygroscopic salt enables ionic conduction, and matches the relative humidity of the hydrogel 
to the average ambient relative humidity. The butyl rubber coating prevents the loss and gain of water due to the daily fluctuation of ambient relative humidity. We develop the chemistry of dip coating the butyl rubber onto the hydrogel, using silanes to achieve both the crosslink of the butyl rubber and the adhesion between the butyl rubber and the hydrogel. We test the endurance of the conductor by soaking it in detergent while stretching it cyclically, and by machinewashing it. The loss of water and salt is minimal. It is hoped that these conductors open applications in healthcare, entertainment, and fashion. 


\section{INTRODUCTION}

The myelinated axon is a hybrid of electrolyte and dielectric. The electrolyte is the saline solution inside and outside the axon. The dielectric is the myelin, the fatty sheath of the axon. The electrolyte-dielectric hybrid is a fast conduit for electrical signal, much like a transmission line, or an earphone ${ }^{1}$. Recent works have mimicked the myelinated axon using a hydrogel as the electrolyte and a hydrophobic elastomer as a dielectric ${ }^{2-4}$. Such a hydrogel-elastomer hybrid, called an artificial axon, or an ionic cable, has enabled many devices of unusual characteristics. Examples include stretchable loudspeaker ${ }^{3}$, sensory $\operatorname{skin}^{4-5}$, electroluminescence ${ }^{6-7}$, and touchpad ${ }^{8}$. Whereas a metal conducts electricity with electrons, a hydrogel conducts electricity with ions. The conductivity of a metal is many orders of magnitude higher than that of a hydrogel. Nonetheless, the hydrogel-elastomer hybrid can transmit electrical signal over long distances (e.g., meters), at high frequencies (e.g., $100 \mathrm{MHz})^{2}$. The hydrogel-elastomer hybrid can be made stretchable, transparent, and biocompatible $e^{9-10}$.

Advances in synthesizing tough hydrogels ${ }^{11-12}$ have suggested that the mechanical behavior of the elastomer-hydrogel hybrid can be made similar to that of stretchable fibers in textiles, such as Spandex ${ }^{\mathbb{O}}{ }^{13}$. Can the artificial axons function as wearable and washable conductors for active textiles? Many stretchable conductors have been developed to enable wearable active textiles ${ }^{14-20}$, but making them washable is challenging ${ }^{21-23}$. Among recent advances, the technology of silver nanowire/PDMS composite stands out. Besides its high conductance over a large range of strain, Huang et al. ${ }^{14}$ have shown that several cycles of machine washing does not degrade the performances of the device." A main hurdle for the elastomer-hydrogel hybrid to function as wearable and washable conductors is the unwanted mass transport, such as the loss of water during wearing, and the loss of salt during washing. Approaches to mitigate the loss of water 
include coating a hydrogel with a hydrophobic elastomer ${ }^{4,24}$, and dissolving a humectant in a hydroge $^{25}$. Neither approach by itself, however, is sufficient for an artificial axon to be wearable and washable under the conditions common for conventional textiles. For example, a polydimethylsiloxane (PDMS)-coated hydrogel fiber, of a diameter about a millimeter, dehydrates in a few hours in the open air; See Table 1 below. A humectant-containing hydrogel swells and de-swells as the humidity in the air varies.

Of all elastomers, butyl rubber has the lowest water permeability. Here we show that a combination of a butyl rubber coating and a humectant will make an artificial axon wearable and washable, even when the artificial axon has the diameter of a textile fiber. The dissolved humectant matches the relative humidity of the hydrogel to the average ambient relative humidity, and the butyl rubber coating minimizes swelling and de-swelling due to daily fluctuation of ambient relative humidity. We show that the permeabilities of the butyl rubber and other elastomers are unaffected by large deformation. We develop a method to dip coat a polyacrylamide hydrogel with a butyl rubber, using silane coupling agents to crosslink the butyl rubber and form strong adhesion between the butyl rubber and hydrogel. Dehydration in open air and salt transport in an aqueous solution are minimized. The artificial axons can be stretched cyclically in detergent, and washed in a washing machine.

\section{COAT AND HUMECTANT}

Soft, low-permeability materials do not exist. Despite the flourishing literature on potential applications of hydrogels as stretchable, transparent, ionic conductors, few commercial devices are available. A stumbling block to transfer the technology to the marketplace is that hydrogels dry out in the ambient conditions. Dehydration slows down when the hydrogels are coated with a 
material of low water permeability. We plot the Young's moduli ${ }^{26-28}$ and the water permeabilities ${ }^{29-35}$ of various materials in one diagram (Figure 1).

Inorganic materials such as silicon dioxides and silicon nitrides have low water permeabilities, and have long been used as hermetic seals for electronic devices. ${ }^{36-38}$ Recently, graphene has been used to seal flexible devices. ${ }^{39}$ Even though nanometer-thin inorganic coatings can be processed, they are stiff and brittle, making them unsuitable as hermetic seals for stretchable devices. Plastics are commonly used as diffusion barriers for food and drugs, but are also too stiff for stretchable devices. Elastomers are stretchable, but the very molecular process making them stretchable also makes them permeable to small molecules. Long polymer chains in an elastomer between crosslinks move ceaselessly. At the scale of monomers, the elastomer is liquid-like, and allows rapid diffusion of molecules smaller than the mesh size of the elastomer. The moduluspermeability space has a large empty region: soft, low-permeability materials do not exist (Figure 1). 


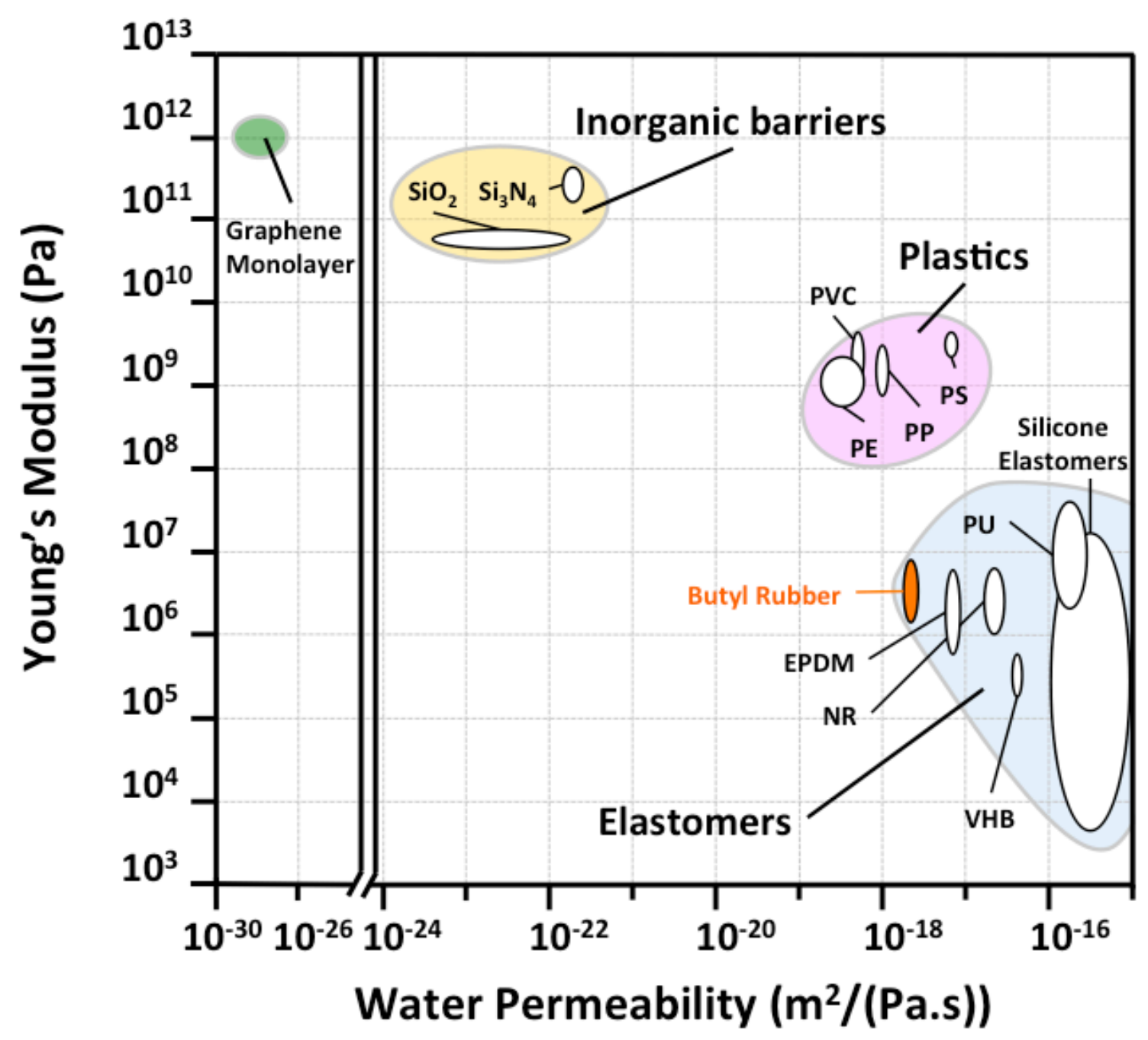

Figure 1. Elastic moduli and water permeabilities of various materials. Soft, low-permeability materials do not exist. Among elastomers, butyl rubber has the lowest water permeability.

Water permeabilities of elastomers vary more than three orders of magnitude ${ }^{29,40-41}$. Butyl rubber (copolymer of isobutylene with a small fraction of isoprene) is by one order of magnitude less permeable to small molecules than other elastomers ${ }^{32,42}$ Butyl rubbers have long been used to make inner linings of tires ${ }^{42}$, medical gloves ${ }^{43}$, and drug-eluting stents ${ }^{44}$. Recently, butyl rubbers have been used as hermetic seals for stretchable electronics ${ }^{45-46}$. Despite its relatively low permeability, butyl rubber is still too permeable to prevent dehydration of hydrogels at the scale of a typical textile fiber; See Table 1 later in the paper. 
Combined effects of elastomeric coating and hygroscopic salt. Many salts are excellent humectants, and their aqueous solutions have relative humidities well below $100 \%{ }^{47-49}$ This effect has been studied recently in hydrogels ${ }^{25}$. Thus, in the artificial axon, a hygroscopic salt serves dual functions: ionic conduction and water retention. However, as noted above, neither an elastomeric coating nor a humectant by itself is sufficient for an artificial axon to be wearable and washable. We show that a combination of a butyl rubber coating and a hygroscopic salt will make an artificial axon to be wearable and washable (Figure 2a). This idea is understood as follows.

The United States Environmental Protection Agency recommends a relative humidity within the range $30-50 \%$ for home and workplace. ${ }^{50}$ Outdoors relative humidity varies from one location to another, with monthly variations (Figure 2b), which have small amplitude, and daily variations, which depends mainly on the time of the day and the local weather ${ }^{51}$ We conducted the following experiments in our lab in Cambridge, Massachusetts, in June-July, 2016. The daily variation of relative humidity was recorded in the lab (Figure 2c), while the mass of several hydrogel-elastomer hybrids was measured (Figure 2d). The hydrogel with no coating and no salts dries rapidly. When the same hydrogel is coated with PDMS $(0.5 \mathrm{~mm})$, the dehydration slows down, but drying is still inevitable. When a hydrogel contains a humectant $(\mathrm{LiCl} 8 \mathrm{M})$, variations of its mass become correlated to the variations of ambient relative humidity in the lab. The gel does not completely dry anymore, but swells and de-swells as the humidity in the ambient changes. The mass variations are quick and with large amplitude. To level those variations, and still avoid the complete drying of the gel over long timescales, we combine those two effects ( 8 $\mathrm{M}$ of $\mathrm{LiCl}$ and $0.5 \mathrm{~mm}$ of PDMS). The gel with both salt and coating is not drying anymore, and the large variations in relative humidity are not generating large variations in mass. 
a

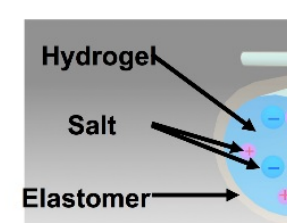

b

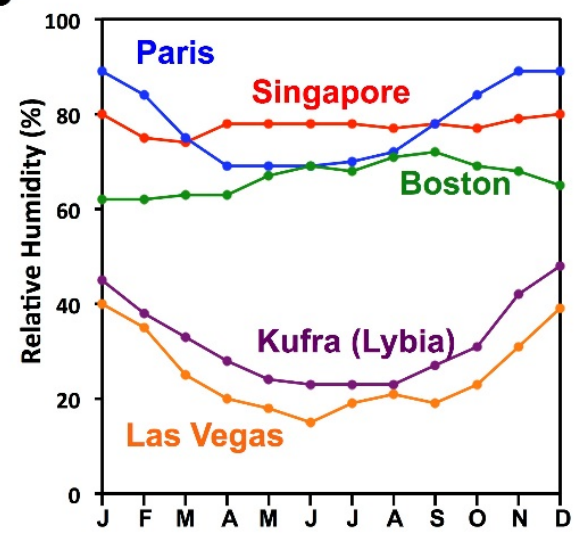

C

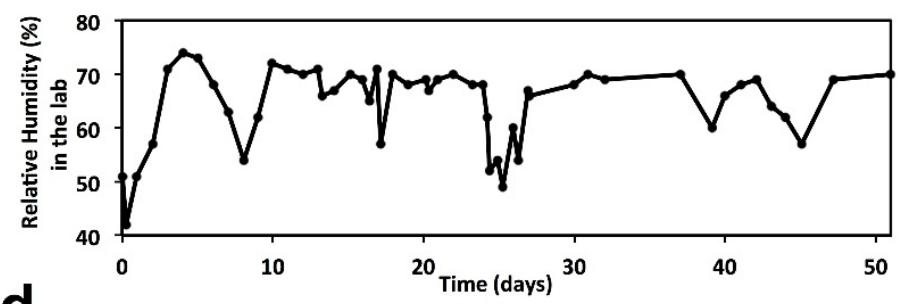

d

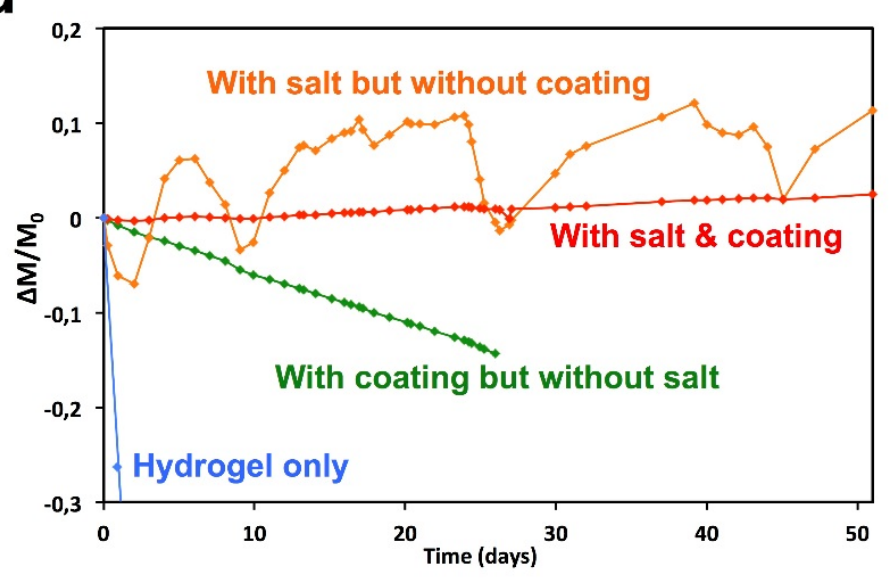

Figure 2. Loss of water of an artificial axon in air. (a) A representative design of an artificial axon consists of a salt dissolved in a hydrogel, coated with an elastomer. (b) Monthly variations of atmospheric relative humidity in several cities around the world. (c) Daily variation of relative humidity in our laboratory in Cambridge, Massachusetts, June-July 2016. (d) The associated variations in the masses of polyacrylamide hydrogels with or without salt $(8 \mathrm{M} \mathrm{LiCl})$ and coating (0.5 mm PDMS).

If the relative humidity of a salt-containing hydrogel matches that in the ambient, there is no driving force for the hydrogel to lose or gain water. Thus, the choice of the humectant (type and concentration) depends on the average relative humidity in the ambient air. For any geometry of device, the surface-to-volume ratio is inversely proportional to the characteristic length scale. Smaller hydrogel-elastomer hybrids will have higher water evaporation rates relatively to their water content. By downscaling all dimensions, a critical size is reached, below which relative 
mass variations becomes too important over the characteristic timescales of the variation of relative humidity. In the following, we try to determine if this critical size is smaller than the scale of textile fibers. We show that only butyl rubber, used with a humectant, is good enough for textile-like applications.

Water permeability of elastomers. Permeability of elastomers to many small molecules has been extensively studied ${ }^{31,40}$, but data for water permeability are less extensive ${ }^{29-30,32-35}$. We measured the water permeability of elastomers using a dry-cup setup (Figure S1). We found that the mass of a cup increased linearly with time (Figure S2a), indicating that steady-state diffusion was reached at short times (less than $24 \mathrm{~h}$ ). In good concordance with the literature, we measure that butyl rubber is approximately 10 times less permeable than $\mathrm{VHB}$, and about 100 times less permeable to water than PDMS (Figure S2b). Recent works on hydrogel-elastomer hybrids often use VHB and PDMS as coatings. ${ }^{4,24}$ Using butyl rubber will increase the lifetime of hydrogelelastomer hybrids in ambient air. Butyl rubber is also an excellent diffusion barrier against other small molecules ${ }^{40}$ and it limits the intrusion of contaminants inside the device. So far as retarding mass transport is concerned, butyl rubber is the material of choice for stretchable devices.

Permeability is essentially independent of large deformation. As applications such as stretchable electronics and soft robots require hermetic seals under large deformations, we also measure the changes in water permeability when elastomers are stretched. When a thin sheet of elastomer is undergoing in-plane stretching, its thickness is reduced because of incompressibility. For an in-plane uniaxial stretch $\lambda$, the thickness is reduced by a factor $\lambda^{1 / 2}$, which will increase the evaporation rate by the same factor. Taking into account the thickness reduction, we measured the water permeability of VHB and butyl rubber thin films under uniaxial stretch (Figure 3). Rectangular elastomer thin films were first clamped on two opposite 
sides between acrylic sheets in order to apply manually the uniaxial stretch in this direction. Then the films were glued on top of cups containing desiccant. A scale $(1 \mathrm{~cm})$ was drawn with a marker in the middle of the thin film before stretching, in order to determine the final uniaxial stretch applied. The dimensions of the thin films were at least three times larger than the cup opening, so that we can consider the stretch to be uniform in the middle of the film. We measured mass variations of the cups with time, using the dry-cup setup again (Figure S1). This is the first time that data of this type are reported. We observe that the water permeability is essentially unaffected by the stretch $\lambda$. Entropic elasticity and diffusion of small molecules are, as a first-order approximation, two independent properties of elastomers. Entropic elasticity is a property of long-chain molecules, while diffusion of small species is related to local vibration of monomers. The two phenomena are related to different length scales and should not be strongly correlated. Elastomers can be used as barrier materials under large deformations.

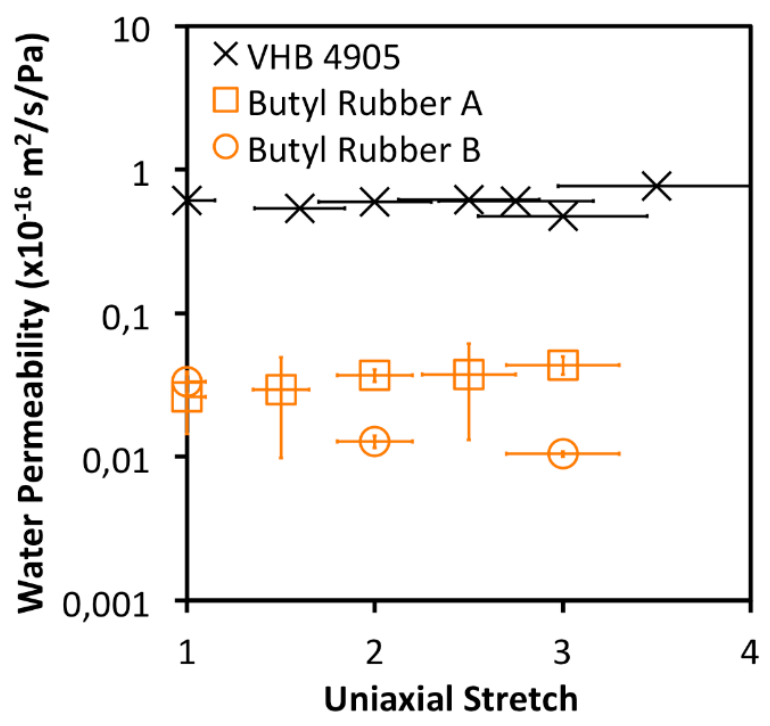

Figure 3. Permeability is essentially independent of stretch. 
Elastomer-coated hydrogel fibers. From the water-permeability measurement, we can evaluate the lifetime of a cylindrical hydrogel fiber (radius R) coated with butyl rubber (thickness h). A characteristic time of diffusion is

$$
\tau_{d i f f}=\frac{h^{2}}{D}
$$

where $\mathrm{D}$ is the diffusion coefficient of water in butyl rubber and $\mathrm{h}$ is its thickness. An estimate by molecular dynamics simulations gives $\mathrm{D}=1.5910^{-11} \mathrm{~m}^{2} / \mathrm{s} .{ }^{52}$ A typical value of $\mathrm{h}$ for a textile fiber coating is $100 \mu \mathrm{m}$, which gives $\tau_{\text {diff }}=10.5$ minutes. The diffusion time is much smaller than the timescale over which the ambient relative humidity is varying (a few hours for a change in weather, or 12 hours for a day-night cycle). Consequently, evaporation of water will reach a steady state in typical ambient conditions. We observed experimentally the rapid establishment of a steady state (Figure S2a) by noticing constant evaporation rates on a timescale much smaller than 12 hours.

The lifetime needed for an artificial axon depends on the type of the elastomer, the radius of the hydrogel $R$, the thickness of the elastomeric coating $h$, as well as the tolerable amount of loss of water. To compare materials and sizes, we choose to use the time needed to lose $20 \%$ of the initial amount of water, $\tau_{20 \%}$. We further assume that the difference in partial pressure of water between the hydrogel and the ambient is constant, $\Delta \Pi$. Using the steady-state diffusion equation for the cylindrical geometry ${ }^{53}$, we find that (S.I.)

$$
\tau_{20 \%}=0.1 \frac{R^{2} \ln (1+h / R)}{P \Delta \Pi}
$$


where $P$ is the water permeability, which is the product of the water diffusivity and solubility in the elastomer. For fixed values of $h / R, P$ and $\Delta \Pi, \tau_{20 \%}$ is quadratic in the radius of the fiber. In the thin-coating limit, $h / R<<1, \ln (1+h / R) \approx h / R$, so that $\tau_{20 \%}=0.1 R h /(P \Delta \Pi)$.

Note that $\Delta \Pi=\prod_{\mathrm{eq}} \Delta \mathrm{RH}$, where $\Delta \mathrm{RH}$ is the difference in the relative humidity between the hydrogel and the ambient, and $\prod_{\mathrm{eq}}$ is the saturated water vapor pressure at a given temperature. Values of $\tau_{20 \%}$ in typical ambient conditions $\left(\Delta \mathrm{RH}=50 \%\right.$ and $\left.\Pi_{e q}=334 \mathrm{OPa}\right)$ are given in Table 1 for PDMS, VHB and butyl rubber, and for two different sizes of fibers. For $\mathrm{R}=2 \mathrm{~mm}$ and $\mathrm{h}=$ $1 \mathrm{~mm}, \tau_{20 \%}$ is about a few days for PDMS, one month for VHB, and one year for butyl rubber. PDMS is too permeable to function as a diffusion barrier for textile-like applications, because daily variations of relative humidity can be large. VHB and butyl rubber can be used to create a water-retaining hybrid over long times, because the average monthly relative humidity vary modestly from month to month (Figure $2 \mathrm{~b}$ ). However, $\mathrm{R}=2 \mathrm{~mm}$ and $\mathrm{h}=1 \mathrm{~mm}$ are unrealistic values for typical textile-like fibers. For $\mathrm{R}=1 \mathrm{~mm}$ and $\mathrm{h}=100 \mu \mathrm{m}$, only butyl rubber has a characteristic lifetime $\tau_{20 \%}$ longer than a few weeks. Under these conditions, butyl rubber is the only elastomer that has a low enough permeability for textile-like applications. 
Table 1. Lifetime of wearable ionic textile

\begin{tabular}{|c|c|c|c|}
\hline & PDMS 20:1 & VHB 4905 & Butyl Rubber ${ }^{a, b}$ \\
\hline $\begin{array}{l}\text { Water-permeability * } \\
\left(1^{-16} \mathrm{~m}^{2} \cdot \mathrm{s}^{-1} \cdot \mathbf{P a}^{-1}\right)\end{array}$ & $2.67 \pm 0.13$ & $0.400 \pm 0.081$ & $\begin{array}{l}0.0256 \pm 0.0075^{\mathrm{a}} \\
0.0334 \pm 0.0061^{\mathrm{b}}\end{array}$ \\
\hline $\begin{array}{l}\boldsymbol{\tau}_{20 \%}(\mathrm{days}) * * \\
\mathbf{R}=\mathbf{2} \mathbf{~ m m}, \mathbf{h}=\mathbf{1} \mathbf{~ m m}\end{array}$ & $4.21 \pm 0.21$ & $28.1 \pm 5.7$ & $\begin{array}{l}439 \pm 129^{\mathrm{a}} \\
337 \pm 62^{\mathrm{b}}\end{array}$ \\
\hline $\begin{array}{l}\tau_{20 \%}(\text { days }) * * \\
R=1 \mathrm{~mm}, \mathrm{~h}=100 \mu \mathrm{m}\end{array}$ & $0.247 \pm 0.012$ & $1.65 \pm 0.34$ & $\begin{array}{l}25.8 \pm 7.6^{\mathrm{a}} \\
19.8 \pm 3.6^{\mathrm{b}}\end{array}$ \\
\hline
\end{tabular}

*: Water-permeabilities have been determined experimentally using a dry-cup setup.

**: $\tau_{20 \%}$ is calculated for a cylindrical geometry of fiber (radius $\mathrm{R}$ and thickness $\mathrm{h}$ of coating), for $\Delta \Pi=1.67 \mathrm{kPa}(\Delta \mathrm{RH}=50 \%)$ at $26^{\circ} \mathrm{C}$.

a: Butyl Rubber A.

${ }^{b}$ : Butyl Rubber B.

Butyl-coated, salt-containing hydrogel fibers. We have showed that butyl rubber can limit mass variations of textile-like fibers over a few weeks, under a large and constant difference in the relative humidity between the hydrogel and the ambient, $\Delta \mathrm{RH}=50 \%$. To avoid losing and gaining water over years, the relative humidity inside the hydrogel must match the annual average relative humidity in the ambient. The annual average relative humidity varies from one location to another, but variations at a location around this annual average are narrowed to 20$30 \%$ (Figure 2b). The relation between salt concentration and relative humidity of electrolyte solutions is well known ${ }^{48}$ and it can be chosen depending on the place of use. Salts like $\mathrm{LiCl}$ and $\mathrm{MgCl}$ can reduce the internal relative humidity of the gel down to $11 \%$ and $33 \%$, respectively. These values are low enough to match the average ambient relative humidity in most places around the world ${ }^{54}$. The driving force of permeation can be - on average - cancelled by this hygroscopic effect, and the relative variations of mass leveled by the butyl rubber. So far as dehydration is concerned, butyl-coated, salt-containing hydrogels of scales of textile fibers can 
have infinite lifetime. However, when reducing the dimensions of the devices, mass variations will eventually become important. According to our estimations, a fiber with a hydrogel fiber radius of $1 \mathrm{~mm}$ and a butyl rubber coating of $100 \mu \mathrm{m}$ will not lose (or gain) more than $20 \%$ of their initial amount of water over a year. According to equation (2), downscaling the dimensions by a factor of 10 would decrease $\tau_{20 \%}$ by a factor of 100 , and the device would dry completely during the period of the year when the relative humidity is lower than the year-average. Designing smaller environmentally-stable devices would require to create elastomers with a water-permeability much lower than butyl rubber.

\section{THE CHEMSTRY OF DIP-COATING BUTYL RUBBER ONTO HYDROGEL}

Our artificial axon is made of an inner fiber of hydrogel containing salt and an outer layer of a butyl rubber. This configuration of elastomer-hydrogel hybrid is used in this paper as a demonstration. The effect of sealing of the elastomer is expected to be similar for other configurations, such as hydrogel-elastomer laminates, and ionic cables containing two hydrogel wires.

Making hydrogel fibers. We made polyacrylamide hydrogel fibers of two types, A and B. Hydrogel A was prepared using a common method (SI). Hydrogel B was prepared by a new method to achieve strong adhesion with the butyl rubber; see description in a later section. For either hydrogel $\mathrm{A}$ and $\mathrm{B}$, the pre-gel solution was injected into a silicone tubing, placed horizontally in a desiccator with a constant nitrogen flux (and exposed to UV in case of Hydrogel B). The hydrogel cured within a few hours. Then the tube was placed in a dichloromethane solution, the silicone tubing swelled, but the hydrogel fiber did not swell and was readily pulled out of the tubing (Figure S3). The hydrogel fiber was then stored in a saline solution (of the same salt concentration as the pre-gel solution) before further experiments. 
Dip coating butyl rubber onto hydrogel fibers. A polyisobutylene solution is casted on the surface of the fiber by dip coating. Dip coating is widely used to make multilayered fibers ${ }^{55-57}$. However, there is no example in the literature of dip coating a hydrophobic coating (butyl rubber) onto a soft and hydrophilic fiber (hydrogel). The pre-solution of butyl rubber was prepared by dissolving long chains of polyisobutylene in a good organic solvent. We prepared two types of butyl rubber, butyl A and butyl B. In both cases (hydrogel A - butyl A and hydrogel B - butyl B), dip coating was performed by hand, with an approximate drawing velocity of 1 $\mathrm{mm} / \mathrm{s}$ (See Video S4). For a single dip coating, the thickness obtained was in the range 20-50 $\mu \mathrm{m}$ for both preparations. Thicker coatings were obtained by repeating dip coating multiple times, by following the same drying procedure for butyl A and B.

Butyl A is a recently developed thermoplastic, in which $\beta$-sheet nanocrystals act as the physical crosslinks ${ }^{58}$. Prior to dip-coating, polyisobutylene (PIB) chains were dissolved in a solution of chloroform and methanol (PIB: $\mathrm{CHCl}_{3}: \mathrm{MeOH}=1 \mathrm{~g}: 10 \mathrm{~mL}: 1 \mathrm{~m}$ ), by stirring at ambient temperature for 12 hours. We dip coated butyl A on top of hydrogel A fibers (S.I Video S4). Upon drying of the organic solvent within 24 to 48 hours, butyl A was automatically crosslinked by the $\beta$-sheet nanocrystals. In this case, polyisobutylene and polyacrylamide do not cross link, resulting in poor adhesion between the butyl rubber and the hydrogel.

Simultaneous crosslinking and bonding of butyl upon dip coating. Achieving strong adhesion between a butyl rubber and a hydrogel is challenging. Most conventional methods to enhance adhesion between soft materials are not applicable. For example, since the precursor of the butyl rubber is in a liquid state before the coating, it is difficult to apply a glue on the interface. Also, since hydrogel consists of more than $80 \%$ volume of water, there is no established way to graft elastomer coating onto hydrogel. Furthermore, crosslinking and bonding 
must be achieved in mild conditions of pressure and temperature, in order to preserve the hydrogel.

Recently we have shown that an elastomer and a hydrogel can form covalent bonds by adding trialkoxysilanes into their precursors. ${ }^{59}$ Upon hydrolysis, a trialkoxysilane generates silanol functional groups, which can condensate into covalent O-Si-O bonds. This condensation reaction is the fundamental mechanism of adhesion. Here we develop this strategy to dip-coat a butyl rubber onto a hydrogel, simultaneously crosslinking the butyl rubber and forming covalent bonds between the butyl rubber and the hydrogel (Figure 4).

We design polyacrylamide hydrogel B to contain two types of crosslinkers: the commonly used MBAA and a trialkoxysilane (TMSPMA) (Figure 4a). They crosslink over different time scales, enabling two distinct steps of fabrication: forming a hydrogel, and dip coating the hydrogel with a butyl rubber. The precursor of the hydrogel was first buffered to $\mathrm{pH}=4$ to slow down the silane condensation inside the hydrogel. For every $10 \mathrm{~mL}$ of AAm solution at $2 \mathrm{M}$ (and salts, typically $\mathrm{NaCl}$ at $2 \mathrm{M}$ ), we added in sequence $200 \mu \mathrm{L}$ of $\alpha$-ketoglutaric acid at $0.1 \mathrm{M}, 40$ $\mu \mathrm{L}$ of MBAA, and $19 \mu \mathrm{L}$ of TMSPMA. We stirred the precursor for one minute to dissolve TMSPMA and then added $100 \mu \mathrm{L}$ of surfactant Brijo L4 at $10^{-3} \mathrm{M}$. TMSPMA rapidly hydrolyzed to form silanol functional groups. The surfactant was used to enhance the efficiency of interfacial coupling with hydrophobic materials. Upon curing under UV exposure, in less than one hour, a polyacrylamide network formed, crosslinked by MBAA. The silane coupling agent was incorporated into the polyacrylamide network. The polyacrylamide network gives the hydrogel a solid form to be handled during dip coating. The dangling silanol functional groups condensate with one another over the course of about three days. Hydrogel B fibers should be dip-coated within one day of fabrication to ensure good adhesion. If the hydrogel were in contact 
with any materials with similar dangling silanol functional groups, the condensation would happen across the interface and form covalent interfacial bonding.

We incorporate a trialkoxysilane into the polyisobutylene chains (Figure 4b). The trialkoxysilane will later crosslink polyisobutylene chains to form butyl rubber, and crosslink polyisobutylene chains and polyacrylamide chains to achieve strong adhesion between the butyl rubber and the hydrogel. The as-received poly(isobutylene-co-isoprene) contains about $98 \%$ isobutylene units and $2 \%$ of isoprene units. The latter contain carbon double bonds intended for sulfur-based vulcanization. Here we employ the thiol-ene click chemistry to graft a trialkoxysilane with a thiol group (MPTMS) onto the isoprene units ${ }^{60}$. The poly(isobutylene-coisoprene) is first dissolved (3g) in cyclohexane (PIB: $\mathrm{C}_{6} \mathrm{H}_{12}=10 \% \mathrm{wt}$ ), and photo-initiator benzophenone $(26.6 \mu \mathrm{L}$ at $0.1 \mathrm{M})$ and MPTMS $(24.7 \mu \mathrm{L})$ are then added into the solution. The solution is put in a transparent glass vial, which is laid horizontally under a UV lamp for 1 hour in order to graft MPTMS to the isoprene units of the polyisobutylene chains through the reaction between the carbon-carbon double bond in the isoprene and the thiol group at the end of MPTMS. We turned the vial every 20 minutes to ensure homogeneous exposure. Since the humidity inside the solution is low, the hydrolysis of trialkoxysilane is slow. The modified precursor can be stored at room temperature for a few days. To crosslink the polyisobutylene upon dip-coating, a tin based catalyst ( $7.1 \mu \mathrm{L}$ of dibutyltin diacetate) is added to the precursor right before the dip coating ${ }^{61}$. Such a catalyst allows the hydrolysis and condensation of the trialkoxysilane even with low humidity.

Since the precursor contains only $10 \% \mathrm{w} / \mathrm{w}$ polybutylisolene, the low concentration of trialkoxysilane and catalyst does not result in fast condensation. We have stored such solution for up to three days at room temperature without noticing any sign of gelation or precipitation. 
However, the film dries after dip coating. The removal of the solvent brings a ten-fold increase in the concentration of both the trialkoxysilane and the catalyst, which significantly accelerates the hydrolysis of the trialkoxysilane to form silanol functional groups, and the condensation of the latter inside the butyl rubber. The condensation of the silanol groups inside the butyl rubber crosslinks the coating. When butyl rubber B is soaked into cyclohexane, it swells, but doesn't dissolve like the poly(isobutylene-co-isoprene) precursor. This observation demonstrates that the butyl B is indeed crosslinked. The condensation of silanol groups between the polyacrylamide and polyisobutylene chains forms covalent bonds between the butyl rubber and the hydrogel. We steam the sample with saturated water vapor at $80{ }^{\circ} \mathrm{C}$ for 12 hours to achieve fast curing. This procedure ensures that residue cyclohexane (with boiling temperature $68^{\circ} \mathrm{C}$ ) in the coating is completely removed, while avoiding premature dehydration of the hydrogel. This method allows the crosslinking and the bonding of butyl rubber at a relatively low temperature range that is compatible with hydrogels. In contrast, conventional sulfur based vulcanization requires $200^{\circ} \mathrm{C}$ temperature. Even silane based crosslinking procedure in hydrophobic polymers often employs curing above $100^{\circ} \mathrm{C}^{61}$. 
a

\section{Polyacrylamide hydrogel}

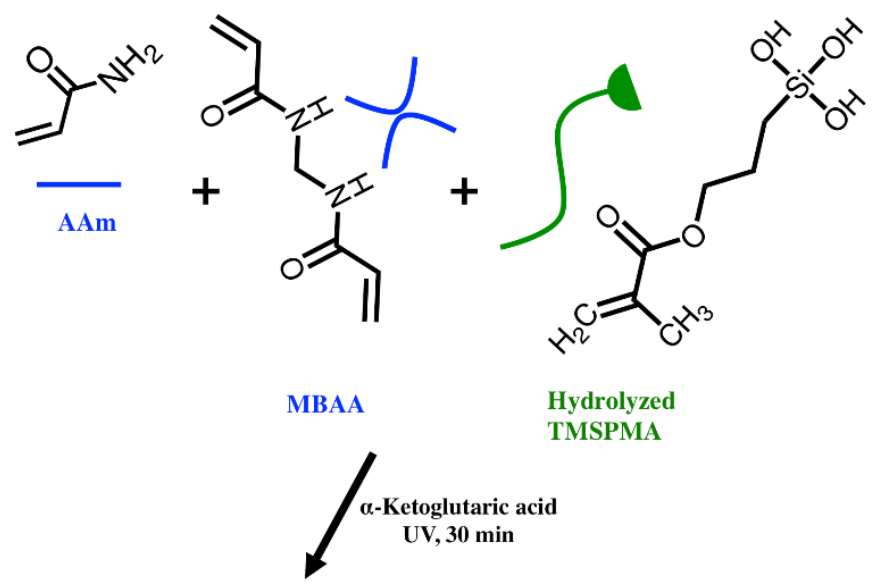

b

Polyisobutylene solution

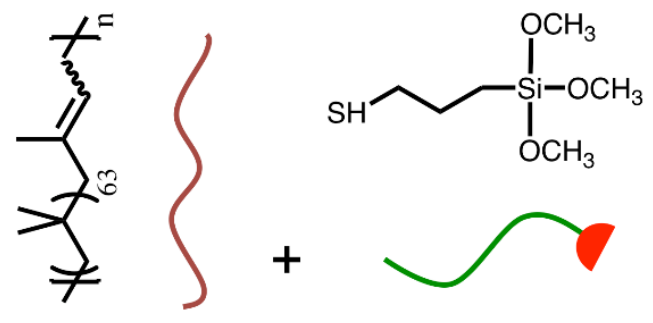

PIB

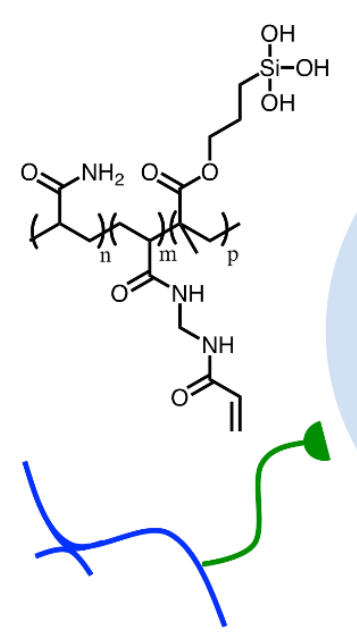

Silane coupling agent
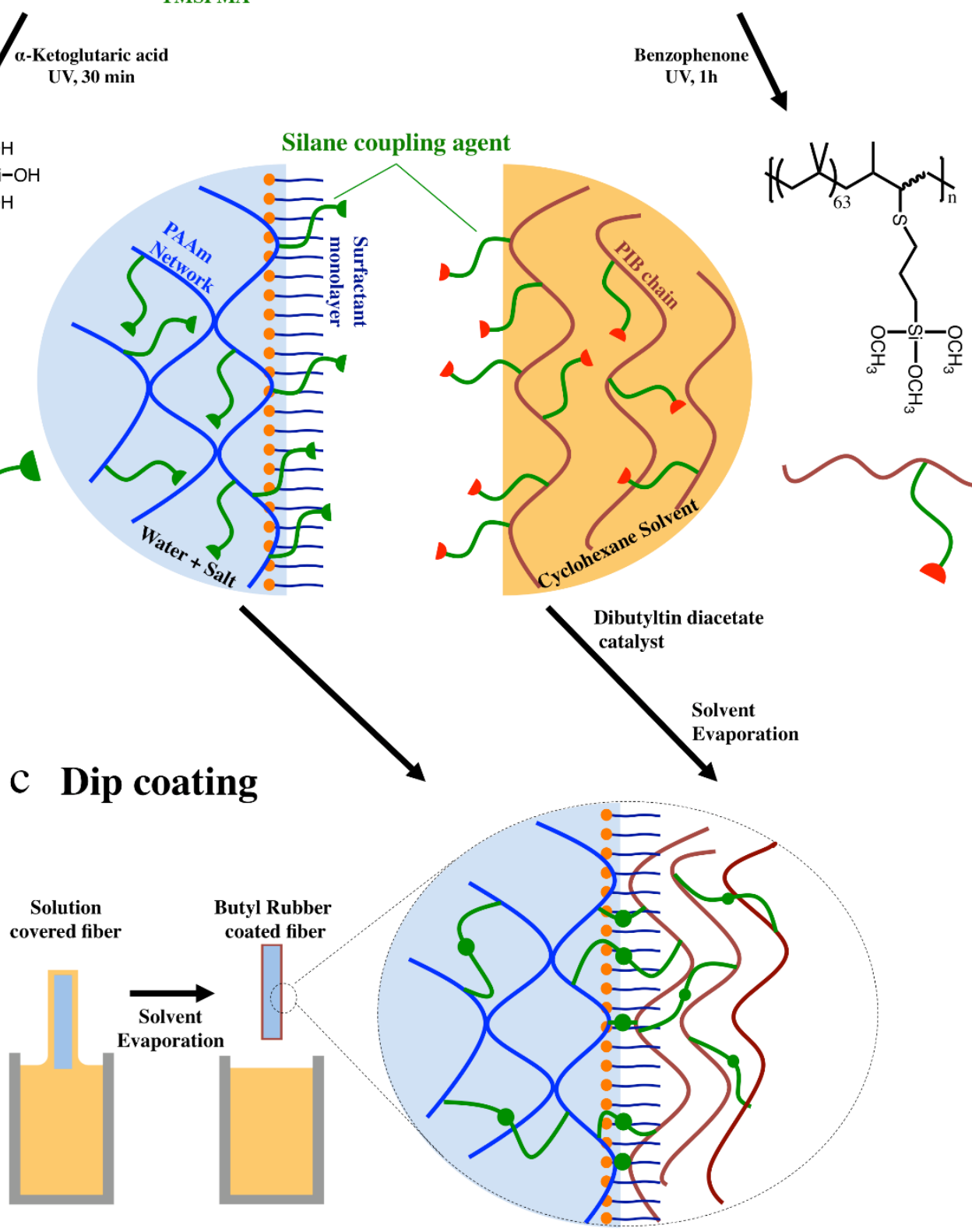
Figure 4. Dip-coating butyl B onto hydrogel B. (a) A polyacrylamide (PAAm) hydrogel forms, with the PAAm chains incorporating a trialkoxysilane coupling agent (TMSPMA). The PAAm chains cross link by MBAA, but not yet by the TMSPMA. The hydrogel also contains a salt $(\mathrm{NaCl})$ and a surfactant (Brij@ L4). (b) The trialkoxysilane coupling agent (MPTMS) reacts with the double bonds in the polyisobutylene (PIB) chains. The PIB chains are not yet crosslinked, and are dissolved in a solvent (cyclohexane) to form a viscous liquid. (c) Dip-coat the hydrogel with the PIB solution. As cyclohexane evaporates, silanes form crosslinks between the PIB chains, the PAAm chains, as well as between the hydrogel and the butyl rubber.

We measured the adhesion energy using a $90^{\circ}$ peeling test (Figure 5a). The interfacial toughness is about $2.37 \pm 0.04(1 \mathrm{STD}) \mathrm{J} / \mathrm{m}$ for the hydrogel A - butyl A interface, and is $79.3 \pm$ 13.9 (1 STD) $\mathrm{J} / \mathrm{m}$ for the hydrogel B - butyl B interface. The adhesion between the butyl B and the hydrogel $\mathrm{B}$ is achieved by the condensation of silanol functional groups. Although the humidity inside the rubber is low, near the rubber-hydrogel interface the trialkoxysilane coupling agent should have plenty of chance to be hydrolyzed by water molecules and form silanol functional groups. Such a thin layer of silanol groups is sufficient to form covalent bonding. Using SEM to observe cross-sections of hydrogel-butyl hybrids, we can see that dip coating generates a uniform thickness of rubber (Figure 5b). In case of butyl B on hydrogel B, the picture has been taken after drying of the fiber. The butyl B coating still shows excellent conformality to the surface of the hydrogel B, possibly due to in-situ bonding. As a result, transparent, soft and stretchable, hydrogel fibers coated with butyl rubber were prepared (Figure 5c). Dip coating and bonding hydrophobic rubbers to hydrophilic hydrogels is possible, and it will help to solve delamination issues in hydrogel-elastomer hybrids. This process is generic and can be applied to a broad range of hydrogels, elastomers, and geometric configurations. 
a
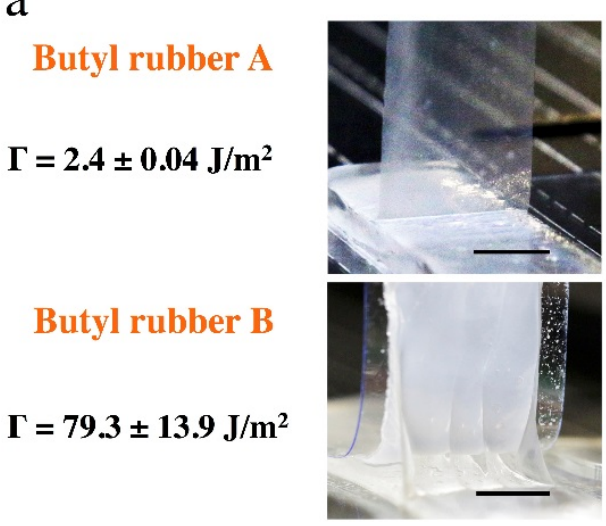

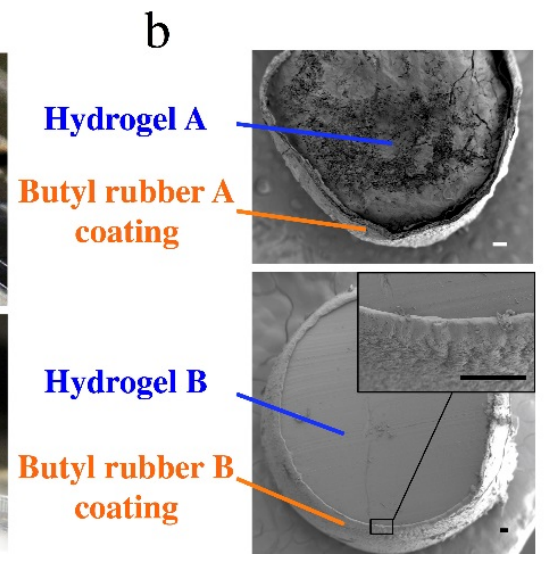

c

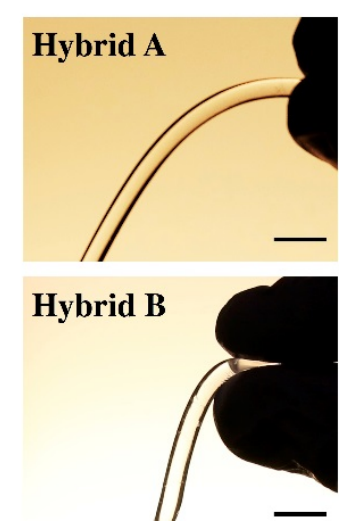

Figure 5. Two types of butyl-coated hydrogel fibers, A and B. (a) Adhesion determined by the $90^{\circ}$ peeling test using an INSTRON ${ }^{\circledR}$ machine. (b) SEM pictures of the cross sections of the butyl-coated hydrogels (scale bar $=200 \mu \mathrm{m})$. (c) Butyl-coated hydrogel fibers (scale bar $=1 \mathrm{~cm}$ ).

\section{ENDURANCE TESTS}

We conduct tests to ascertain if the butyl-coated hydrogels can retain water during wearing in the open air, and retain salt during washing in a washing machine.

In-air and in-water use of butyl rubber-coated hybrids. Butyl rubber coatings can considerably slow down the loss of mass (Figure 6). Fibers were placed in a closed chamber containing a large amount of desiccant. Relative humidity inside the chamber is below $5 \%$, taken to be $0 \%$ with a $5 \%$ uncertainty. For this experiment, the hydrogel fibers diameter was $4.8 \mathrm{~mm}$, and their length was $8 \mathrm{~cm}$. Relative humidity of the hydrogels was taken to be $100 \%$ because they did not contain any salts. The coated sample had a $20( \pm 5) \mu$ m-thick coating of butyl A. Dip coating (instead of solvent casting for the water-permeability measurements) does not affect the excellent barrier properties of the butyl rubber. Furthermore, sufficiently thin coatings (less than $100 \mu \mathrm{m}$ ) can be processed to design hybrids at the typical size of textile fibers. 


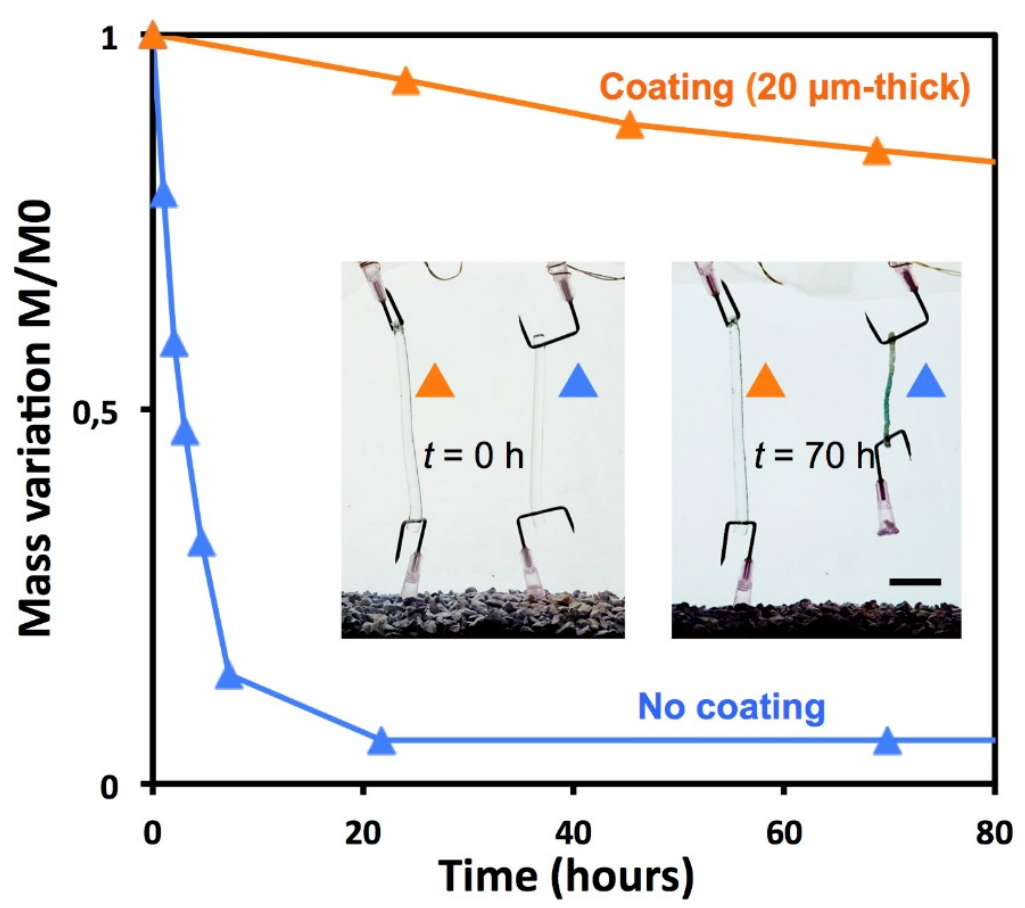

Figure 6. Loss of mass of hydrogel fibers with and with coating in a dry atmosphere (RH $\leq 5 \%)$. Hydrogel A and butyl A were used. The insets are photos taken at time zero and 70 hours of the hydrogel fibers with or without the butyl rubber coating. Scale bar $=1 \mathrm{~cm}$.

Hydrogels containing hygroscopic salts can theoretically have an infinite lifetime if their relative humidity matches the average outside relative humidity. We next verify that a butyl rubber coating can also slow down diffusion of salts over a long time. Salt diffusion has been studied for polymers used as semi-impermeable membranes for desalinization ${ }^{62}$ or plastics in the food packaging industry ${ }^{63}$, but there is no study of salt diffusion in elastomers.

We designed an experiment to measure the loss of salt (Figure 7). We soaked butyl rubbercoated, NaCl-containing hydrogels in a deionized water bath, while monitoring the electrical conductance of the bath, and the resistance of the hydrogels with time. The fibers $(6.4 \mathrm{~mm}$ of diameter and $10 \mathrm{~cm}$ long) were bended in a U-shape and immerged in $500 \mathrm{~mL}$ of deionized 
water over a $5 \mathrm{~cm}$ of length. Conductance $\mathrm{G}$ of the bath was measured with time using a Conductivity meter (VWR® Traceable ${ }^{\circledR}$ Pens ; 89094-762). For this geometry, and an initial $\mathrm{NaCl}$ concentration of $1.71 \mathrm{M}$ (i.e. $10 \%$ wt of the water content in the hydrogel), the maximum value of $\mathrm{G}$ is $\mathrm{G}_{\max }=973 \mathrm{mS}$ (steady value reached after a few hours for a hydrogel fiber without coating). Electrical wires were attached to both ends of the fibers with a stainless steel hook. The hooks were added to the hydrogel fiber before dip coating, so that butyl rubber would also protect the hydrogel-metal interface. We only applied sinusoidal electrical signals at a frequency of $1 \mathrm{kHz}$ using a wave generator (Keysight 33500B) to limit electrochemical reactions at the metal-hydrogel interconnects. For each data point, the resistance $\mathrm{R}$ of the fiber was measured through the current-voltage curve, based on four-point measurements. Applied voltages were 0.1, 0.45, 0.8 and 1.0 V. Current was measured with a Fluke 8846A Multimeter. During each measurement, the fiber was pulled out of the bath in order to avoid short circuit. $\mathrm{R}_{0}$ is the value of the resistance, for a given sample, at time $t=0$. For instance, $R_{0}=563 \Omega$ for a sample without coating and $\mathrm{R}_{0}=548 \Omega$ for a sample with $160 \mu \mathrm{m}$-thick coating at ambient temperature. We carried out the experiment at 20 and $50^{\circ} \mathrm{C}$ for two thicknesses of coating (obtained by repeated dip coating), 160 and $240 \mu \mathrm{m}$. Samples with a $240 \mu \mathrm{m}$-thick coating had no electrodes at the ends, and only the bath conductance was measured. Measurements for samples with and without electrodes are similar, which confirms that there is no leak of salt at interconnects with electrodes. Metallic hooks piercing through the end of the ionic cable are not a viable solution for interconnects, because isolation may be compromised at the interface, and adhesion between the hydrogel and the metallic hook is not achieved in our experiment. As shown by Yuk et al. ${ }^{24}$, strong bonding can be achieved between a metal and a hydrogel. The same chemistry can be used to graft a metallic cap at each end of the cable. This step can be down prior to dip coating, during the curing of the gel inside the silicone tubing. Butyl rubber would then wrap the 
hydrogel-metal interface after the dip coating. Conventional female-to-male connection could be achieved to plug the butyl rubber coated hydrogel into conventional electronics.

It takes about $10^{4}$ more time to reach a given value of conductance in the bath when a butyl coating of about $200 \mu \mathrm{m}$ protects the fiber. Diffusion of salt through the coating is not affected by a change in temperature from 20 to $50^{\circ} \mathrm{C}$. Over a time of one hour, diffusion of salt in the bath is negligible for the hybrid (less than $0.1 \%$ of the maximum conductivity $G_{\max }$ is reached). Similarly, the resistance of the fiber is not quantitatively increased over the same timescale. The hybrid can be used in water for hours without leaking salt in its environment. This property should also be significant in the development of stretchable electronic embedded in living tissues or bodies.

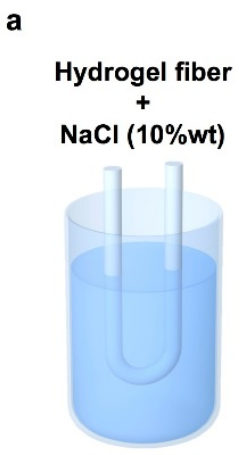

DI Water
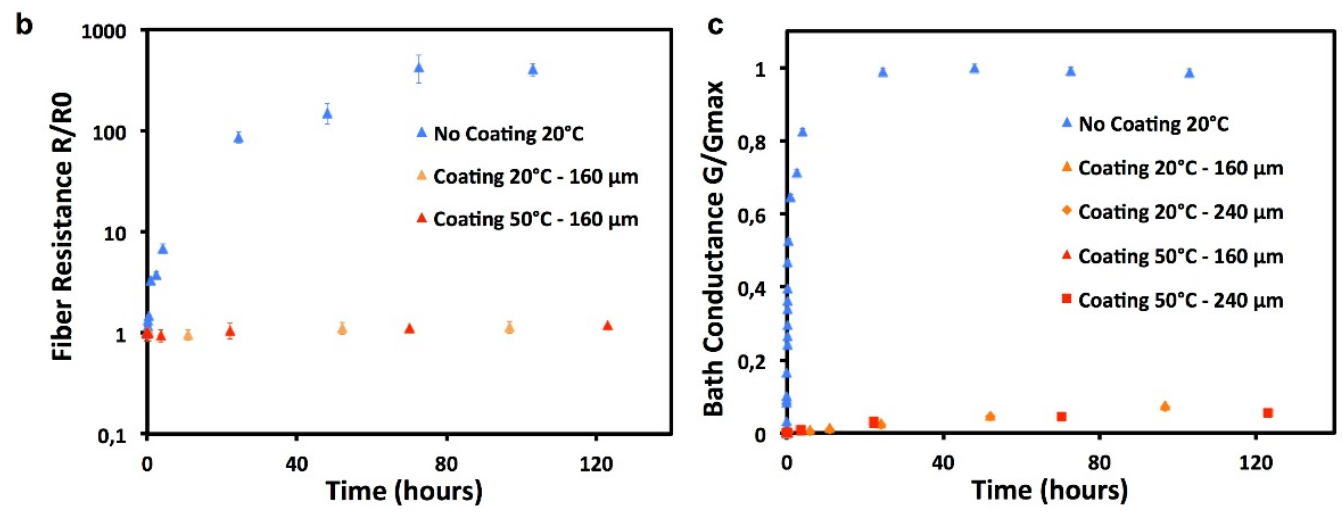

Figure 7. (a) The setup used to measure $\mathrm{NaCl}$ diffusion through butyl coatings. (b) Relative resistance of the fibers change with time. (c) Relative conductance of the bath changes with time.

Washing. We define "washable" as the property of a device to undergo mechanical deformations under water without major losses of mechanical and electrical properties. We designed two experiments to demonstrate that the butyl-coated hydrogels are washable.

First, we soaked the fibers cyclically in a heated bath $\left(40^{\circ} \mathrm{C}\right)$ containing a blue dye and soap (Sodium Dodecyl Sulfate, $5 \mathrm{mM}$ ), while stretched the fibers cyclically using an INSTRON ${ }^{\circledR}$ 
machine (Figure 8a). The minimum stretch applied was $\lambda=\mathrm{L} / \mathrm{L}_{0}=1\left(\mathrm{~L}_{0}=5 \mathrm{~cm}\right)$ and the maximum stretch applied was $\lambda=1.5$. Extension rate was $5 \mathrm{~mm} / \mathrm{s}$. We acquired 10 current-voltage points to determine the resistance of the fiber. The standard deviation is calculated for this dataset, before and after washing (Figure $8 \mathrm{~b}$ ). We performed the experiment on two fibers (length $\mathrm{L}_{0}$, diameter $4.8 \mathrm{~mm})$ : one without coating, and one with a $50 \mu \mathrm{m}( \pm 10 \mu \mathrm{m})$ - thick coating of butyl A. After one hour of washing, the resistivity of the hybrid does not vary quantitatively, and it shows no signs of diffusion of the blue dye through the coating. We have shown that water-permeability is not affected by uniaxial stretch (Figure 3), and we can infer from those results that the same applies probably to the salt, dye, and soap permeability in the butyl rubber.

a
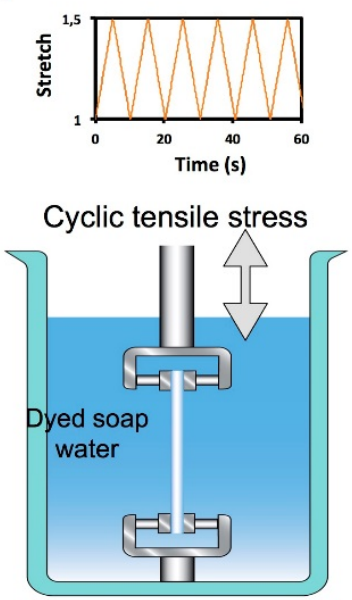

b

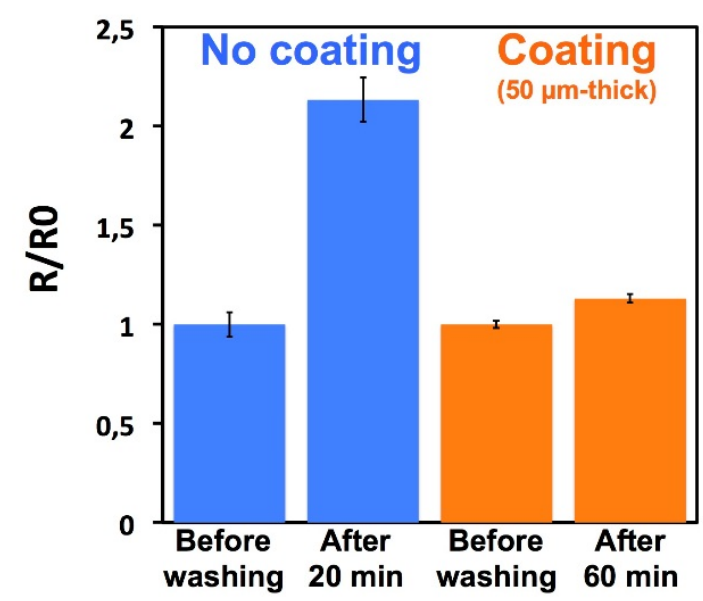

C

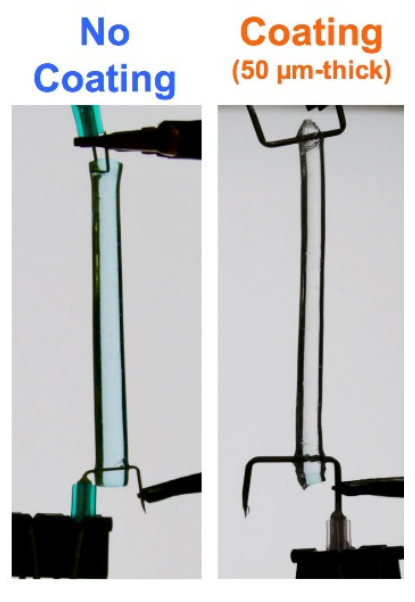

Figure 8. (a) The INSTRON ${ }^{\circledR}$ setup used to stretch fibers in a simulated washing environment. (b) Relative resistance of samples before and after washing. (c) Pictures of the fibers with and without coating after washing. Change in color shows that the fiber without coating absorbs the blue dye in the bath.

The second experiment corresponds to more realistic conditions - although less controllable. We washed the butyl rubber-coated hydrogels using a washing machine (Maytag Commercial 
MHN30PRCWW 27"), with a "normal" washing program, lasting 35 minutes at $40^{\circ} \mathrm{C}$, named "white and colors". We prepared 11 samples with the same length and diameter $\left(\mathrm{L}_{0}=8 \mathrm{~cm}, 4.8\right.$ $\mathrm{mm}$ of diameter), containing an initial $\mathrm{NaCl}$ concentration of $2 \mathrm{M}$ and dip coated (one single time) butyl A. The coating's thickness of each sample was measured (using the vernier scale, 10 $\mu$ m-precision) after the last cycle of washing, because the fiber needed to be cut in order to remove a part of the coating. Thicknesses range from 20 to $40 \mu \mathrm{m}$ with a Standard Deviation of 8 $\mu \mathrm{m}$ on the dataset. Precision on each measurement could be improved to $5 \mu \mathrm{m}$ instead of $10 \mu \mathrm{m}$, because the hollow cylindrical coating was flattened and the double of the thickness was measured each time. We embedded each hybrid in the hemline of a sock (Figure 9a), and put the socks in the machine. We washed the samples multiple times, using the same program $\left(40^{\circ} \mathrm{C}, 35\right.$ min), and monitored the resistance and mass of the samples after washing (Figure 9b). For each sample, we could only measure the resistance once, because it requires piercing through the coating with metallic electrodes, which would have affected further washing cycles. We estimated $\mathrm{R}_{0}$ based on the mean resistance of 3 samples that were washed 0 times. We went up to 5 cycles of washing, and no significant loss or gain of mass or resistance is detected. The integrity of the coating is still very good (homogeneity, smooth surface, and transparency) (Figure 9c). 
a

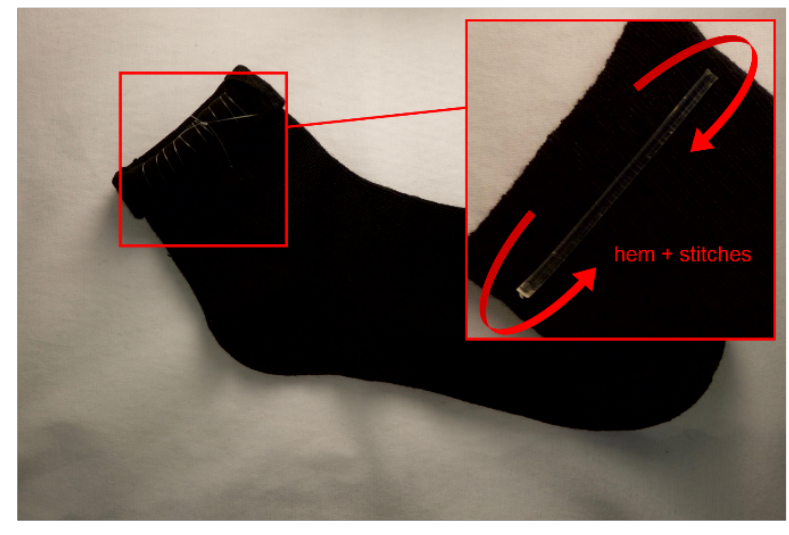

b

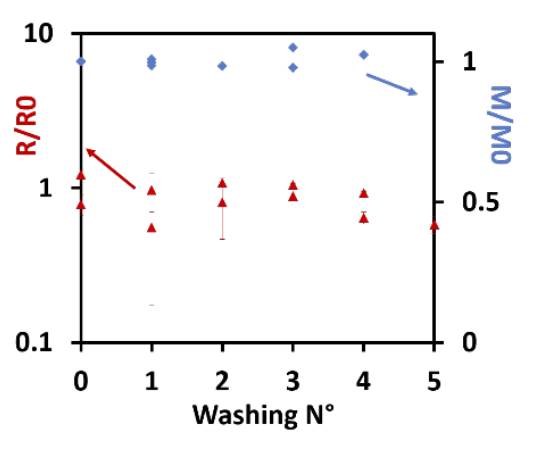

C

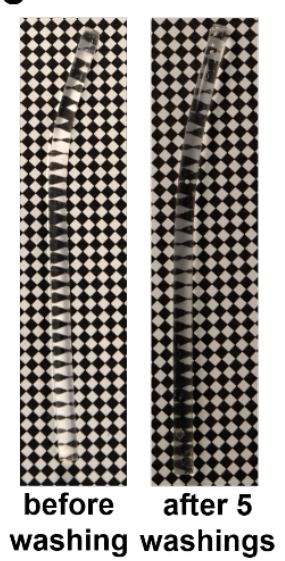

Figure 9. Washing butyl-coated hydrogels in a washing machine. (a) Embedding fibers (hydrogel A coated with butyl A) in socks prior to washing in a real washing machine. (b) Relative resistance of the fibers and mass variations after multiple cycles of washing. (c) Picture of a fiber coated with butyl A before any washing cycle, and after 5 cycles. Washing is not detrimental to the mechanical and electrical stability of the artificial axon.

\section{CONCLUSIONS}

We have developed a new class of wearable and washable conductors for active textiles. No soft, low-permeability material exists to prevent dehydration, by itself, at the size scale of textile fibers. However, a thin film of butyl rubber, aided with a humectant, makes a hydrogel a wearable and washable conductor. We have developed the chemistry to dip coat the butyl rubber onto the hydrogel, using silane condensation reaction to crosslink the butyl rubber, and to from strong adhesion between the butyl rubber and the hydrogel. The fibers retain water in the open air, and retain slat during washing. The elastomer retains its low permeability under large deformation. Durable artificial axons under practical conditions will enable broad applications in healthcare, entertainment, and fashion. Butyl rubbers, as well as the silane chemistry, are also compatible with roll-to-roll and digital fabrication, as well as manual assembly. It can be 
laminated to other elastomers to enable soft robots, and artificial nerves, much like the liners of tubeless tires. The elastic modulus of butyl rubber can be tuned over a large range to be as soft as tissues. The permeability is insensitive to such modifications. Dip coating of hydrogels also open the possibility to combine a broad range of properties by overlaying multiple layers of soft materials. Tires are multifunctional because they use multiple materials. The same principle is applicable to design artificial axons.

MATERIALS. Acrylamide (AAm ; A8887), N,N-methylenebisacrylamide (MBAA ; 146072), $N, N, N^{\prime}, N^{\prime}$-Tetramethylethylenediamine (TEMED ; T9281), Ammonium Persulfate (APS ; A9164), Sodium Chloride ( $\mathrm{NaCl}$; S7653), Lithium Chloride (LiCl ; L4408), Dichloromethane $\left(\mathrm{CH}_{2} \mathrm{Cl}_{2} ; 270997\right)$, Chloroform $\left(\mathrm{CHCl}_{3} ; 372978\right)$, Cyclohexane $\left(\mathrm{C}_{6} \mathrm{H}_{12} ; 227048\right)$, (3Mercaptopropyl)trimethoxysilane (MPTMS ; 175617), 3-(Trimethoxysilyl)propyl methacrylate (TMSPMA ; 440159), Benzophenone (427551), Polyethylene glycol dodecyl ether (Brij ${ }^{\circledR}$ L4 ; 235989), $\alpha$-Ketoglutaric Acid (K1750), Dibutyltin diacetate (290890) were all purchased from Sigma-Aldrich. The butyl rubber precursor (Exxon Butyl $268 \mathrm{~S}^{\circ}$ ) was donated by Vanderbilts Chemicals. Other elastomers were purchased from various suppliers: Polydimethylsiloxane (PDMS ; Sylgard ${ }^{\circledR} 184$; Dow Corning), Ecoflex (00-30 ; Smooth-On), Acrylonitrile rubber (Kimberly-Clark) and VHB (4905 ; 3M). Cyanoacrylate-based Krazy Glue ${ }^{\oplus}$ was used to seal elastomeric thin films on top of containers for dry/wet-cup set ups. Calcium sulfate dihydrate $\left(\mathrm{CaSO}_{4}, 2 \mathrm{H}_{2} \mathrm{O}\right.$; Alfa Aesar) was used as a desiccant. In all the experiments, we used Poland Spring ${ }^{\circledR}$ Distilled Water as deionized water supply. To prepare hydrogel fibers, we cured the gels inside cylindrical soft tubings (Cole-Parmer, SKU $n^{\circ} 95802-00, \mathrm{n}^{\circ} 95802-03, \mathrm{n}^{\circ} 95802-04$, with respective inner diameters $0.51 \mathrm{~mm}, 2.39 \mathrm{~mm}, 3.17 \mathrm{~mm}$, as shown on Figure S3). For 
measurements of permeabilities using a "cup" based setup, we used the bottom part of Micro Dish (35 x 100 mm ; 10799-192 ; VWR ${ }^{\circledR}$ ), or Testing Jars (42 x 83 mm; 10862-214; VWR $\left.{ }^{\circledR}\right)$, as containers.

\section{ASSOCIATED CONTENT}

\section{Supporting Information}

The theory of permeability applied to the mass transport of water in an elastomer. Derivation of the lifetime of an elastomer-coated hydrogel fiber. Dry-cup setup for water permeability measurements (Figure S1). Experimental measurements of water permeability (Figure S2). Preparation of hydrogel fibers (Figure S3). Dip coating a hydrogel fiber with butyl rubber (Video S4).

\section{AUTHOR INFORMATION}

Corresponding Author

suo@seas.harvard.edu

\section{ACKNOWLEDGMENT}

\section{Funding Sources}


The work at Harvard is supported by the NSF MRSEC (DMR-1420570). The work at Akron is supported by the NSF (DMR-1610109). 


\section{REFERENCES}

1. Dayan, P., Abbott, L. F. , Theoretical Neuroscience: Computational And Mathematical Modeling of Neural Systems Massachusetts Institute of Technology Press 2005.

2. Yang, C. H.; Chen, B.; Lu, J. J.; Yang, J. H.; Zhou, J.; Chen, Y. M.; Suo, Z., Ionic Cable Extreme Mech. Lett. 2015, 3, 59-65.

3. Keplinger, C.; Sun, J.-Y.; Foo , C. C.; Rothemund, P.; Whitesides, G. M.; Z., S., Stretchable, Transparent, Ionic Conductors Science 2013, 341, 984-987.

4. Sun, J. Y.; Keplinger, C.; Whitesides, G. M.; Suo, Z., Ionic Skin Adv. Mater. 2014, 26, 7608-7614.

5. Robinson, S. S.; O’Brien, K. W.; Zhao, H.; Peele, B. N.; Larson, C. M.; Mac Murray, B. C.; Van Meerbeek, I. M.; Dunham, S. N.; Shepherd, R. F., Integrated Soft Sensors and Elastomeric Actuators for Tactile Machines with Kinesthetic Sense Extreme Mech. Lett. 2015, 5, 47-53.

6. Yang, C. H.; Chen, B.; Zhou, J.; Chen, Y. M.; Suo, Z., Electroluminescence of Giant Stretchability Adv. Mater. 2016, 28, 4480-4484.

7. Larson, C.; Peele, B.; Li, S.; Robinson, S.; Totaro, M.; Beccai, L.; Mazzolai, B.; Sheperd, R., Highly Stretchable Electroluminescent Skin for Optical Signaling and Tactile Sensing Science 2016, 351, 1071-1074.

8. Kim, C.-C.; Lee, H.-H.; Oh, K. H.; Sun, J.-Y., Highly Stretchable, Transparent Ionic Touch Panel Science 2016, 353, 682-687. 
9. Puskas, J. E.; Chen, Y.; Dahman, Y.; Padavan, D., Polyisobutylene-based Biomaterials $J$. Polym. Sci., Part A-1: Polym. Chem. 2004, 42, 3091-3109.

10. Puskas, J. E.; Chen, Y., Biomedical Application of Commercial Polymers and Novel Polyisobutylene-Based Thermoplastic Elastomers for Soft Tissue Replacement Biomacromolecules 2003, 5, 1141-1154.

11. Gong, J. P.; Katsuyama, Y.; Kurokawa, T.; Osada, Y., Double-Network Hydrogels with Extremely High Mechanical Strength Adv. Mater. 2003, 15, 1155-1158.

12. Sun, J.-Y.; Zhao, X.; Illeperuma, W. R. K.; Chaudhuri, O.; Oh, K. H.; Mooney, D. J.; Vlassak, J.; Suo, Z., Highly Stretchable and Tough Hydrogels Nature 2012, 489, 133-136.

13. Hicks, E. M.; Ultee, A. J.; Drougas, J., Spandex Elastic Fibers Science 1965, 147, 373379.

14. Huang, G. W.; Xiao, H. M.; Fu, S. Y., Wearable Electronics of SilverNanowire/Poly(dimethylsiloxane) Nanocomposite for Smart Clothing Sci.Rep. 2015, 5, 13971.

15. Zeng, W.; Shu, L.; Li, Q.; Chen, S.; Wang, F.; Tao, X. M., Fiber-based Wearable Electronics: a Review of Materials, Fabrication, Devices, and Applications Adv. Mater. 2014, 26, $5310-5336$.

16. Hu, L.; Pasta, M.; Mantia, F. L.; Cui, L.; Jeong, S.; Deshazer, H. D.; Choi, J. W.; Han, S. M.; Cui, Y., Stretchable, Porous, and Conductive Energy Textiles Nano. Lett. 2010, 10, 708-714.

17. Lipomi, D. J.; Bao, Z., Stretchable, Elastic Materials and Devices for Solar Energy Conversion Energy Environ. Sci. 2011, 4, 3314-3328. 
18. Minev, I. R.; Musienko, P.; Hirsch, A.; Barraud, Q.; Wenger, N.; Moraud, E. M.; Gandar, J.; Capogrosso, M.; Milekovic, T.; Asboth, L.; Torres, R. F.; Vachicouras, N.; Liu, Q.; Pavlova, N.; Duis, S.; Larmagnac, A.; Vörös, J.; Micera, S.; Suo, Z.; Courtine, G.; Lacour, S. P., Electronic Dura Mater for Long-term Multimodal Neural Interfaces Science 2015, 347, 159-163.

19. Kim, D.-H.; Rogers, J. A., Stretchable Electronics: Materials Strategies and Devices $A d v$. Mater. 2008, 20, 4887-4892.

20. Rogers, J. A.; Someya, T.; Huang, Y., Materials and Mechanics for Stretchable Electronics Science 2010, 327, 1603-1607.

21. Vervust, T.; Buyle, G.; Bossuyt, F.; Vanfleteren, J., Integration of Stretchable and Washable Electronic Modules for Smart Textile Applications J. Text. Inst. 2012, 103, 11271138.

22. Kellomäki, T.; Virkki, J.; Merilampi, S.; Ukkonen, L., Towards Washable Wearable Antennas: A Comparison of Coating Materials for Screen-Printed Textile-Based UHF RFID Tags Int. J. Antennas Propag. 2012, 2012, 476570.

23. Yang, Y.; Huang, Q.; Niu, L.; Wang, D.; Yan, C.; She, Y.; Zheng, Z., Waterproof, Ultrahigh Areal-Capacitance, Wearable Supercapacitor Fabrics Adv. Mater. 2017, 29, 1606679.

24. Yuk, H.; Zhang, T.; Parada, G. A.; Liu, X.; Zhao, X., Skin-inspired Hydrogel-Elastomer Hybrids with Robust Interfaces and Functional Microstructures Nat. Commun. 2016, 7, 12028.

25. Bai, Y.; Chen, B.; Xiang, F.; Zhou, J.; Wang, H.; Suo, Z., Transparent Hydrogel with Enhanced Water Retention Capacity by Introducing Highly Hydratable Salt Appl. Phys. Lett. 2014, 105, 151903. 
26. Mark, J. E., Physical Properties of Polymers Handbook 2 ed.; Springer 2007.

27. Ashby, M. F., Materials Selection in Mechanical Design 4 ed.; Elsevier Ldt. 2011.

28. Cai, L. H.; Kodger, T. E.; Guerra, R. E.; Pegoraro, A. F.; Rubinstein, M.; Weitz, D. A., Soft Poly(dimethylsiloxane) Elastomers from Architecture-Driven Entanglement Free Design Adv. Mater. 2015, 27, 5132-5140.

29. Wolff, E. G., Introduction to the Dimensional Stability of Composite Materials, DEStech Publications 2004.

30. Helander, R. D. In Water Vapor Transmission Rate (WVTR) of Elastomeric Materials, SAMPE Symposium, 1984; pp 1373-1383.

31. McKeen, L. W., Permeability Properties of Plastics and Elastomers 3 ed.; Elsevier 2012.

32. Iyengar, Y., Relation of Water Vapor Permeability of Elastomers to Molecular Structure Polym. Lett. 1965, 3, 663-669.

33. Illinger, J. L.; Schneider, N. S., Water Vapor Transport in Hydrophilic Polyurethanes. In Permeability of Plastic Films and Coatings, 1974; pp 183-196.

34. Barrie, J. A.; Machin, D.; Nunn, A., Transport of Water in Synthetic cis 1,4 Polyisoprene and Natural Rubber Polymer 1975, 16, 811-814.

35. Aminabhavi, T. M.; Thomas, R. W.; Cassidy, P. E., Predicting Water Diffusivity in Elastomers Polym. Eng. Sci. 1984, 24, 1417-1420. 
36. Visweswaran, B.; Mandlik, P.; Mohan, S. H.; Silvernail, J. A.; Ma, R.; Sturm, J. C.; Wagner, S., Diffusion of Water into Permeation Barrier Layers J. Vac. Sci.Technol., A 2015, 33, 031513.

37. Hanada, T.; Negishi, T.; Shiroishi, I.; Shiro, T., Plastic Substrate with Gas Barrier Layer and Transparent Conductive Oxide Thin Film for Flexible Displays Thin Solid Films 2010, 518, 3089-3092.

38. Tsai, M.-H.; Wang, H.-Y.; Lu, H.-T.; Tseng, I. H.; Lu, H.-H.; Huang, S.-L.; Yeh, J.-M., Properties of Polyimide/A12O3 and Si3N4 deposited Thin Films Thin Solid Films 2011, 519, 4969-4973.

39. Seethamraju, S.; Kumar, S.; B, K. B.; Madras, G.; Raghavan, S.; Ramamurthy, P. C., Million-Fold Decrease in Polymer Moisture Permeability by a Graphene Monolayer ACS Nano 2016, 10, 6501-6509.

40. Van Amerongen, G. J., The Permeability of Different Rubbers to Gases and Its Relation to Diffusivity and Solubility J. Appl. Phys. 1946, 17, 972-985.

41. Van Amerongen, G. J., Influence of Structure of Elastomers on Their Permeability to Gases J. Polym. Sci. 1949, 5, 307-332.

42. Haworth, J. P.; Baldwin, F. P., Butyl Rubber Properties and Compounding Ind. Eng. Chem. 1942, 34, 1301-1308.

43. Darre, E.; Vedel, P., Surgical Rubber Gloves Impervious to Methylmethacrylate Monomer Acta Orthop. Scand. 1984, 55, 254-255. 
44. Puskas, J. E.; Munoz-Robledo, L. G.; Hoerr, R. A.; Foley, J., Drug-eluting Stent Coatings WIREs Nanomed. Nanobiotechnol. 2009, 1, 451-462.

45. Vohra, A.; Carmichael, R. S.; Carmichael, T. B., Developing the Surface Chemistry of Transparent Butyl Rubber for Impermeable Stretchable Electronics Langmuir 2016, 32 (40), 10206-10212.

46. Vohra, A.; Filiatrault, H. L.; Amyotte, S. D.; Carmichael, R. S.; Suhan, N. D.; Siegers, C.; Ferrari, L.; Davidson, G. J. E.; Carmichael, T. B., Reinventing Butyl Rubber for Stretchable Electronics Adv. Func. Mater. 2016, 26 (29), 5222-5229.

47. Stokes, R. H.; Robinson, R. A., Ionic Hydration and Activity in Electrolyte Solutions $J$. Am. Chem. Soc. 1948, 70 (5), 1870-1878.

48. Young, J. F., Humidity Control in the Laboratory using Salt Solutions - a Review J. appl. Chem. 1967, 17, 241-245.

49. Greenspan, L., Humidity Fixed Points of Binary Saturated Aqueous Solutions J. Res. Natl. Bur. Stand., Sect. A 1977, 81A, 89-96.

50. EPA United States Environmental Agency. Fundamentals of Indoor Air Quality (IAQ) in Buildings. https://www.epa.gov/indoor-air-quality-iaq/fundamentals-indoor-air-quality-buildings (July 10, 2017).

51. Calheiros De Miranda, R. A.; Milde, L. C. E., Daily Characterization of Air Temperature and Relative Humidity Profile in a Cocoa Plantation Pesq. agrospec. bras. 1994, 29, 345-353. 
52. Faulon, J.-L.; Hobbs, J. D.; Ford, M. D.; Wilcox, R. T. In Massively Parallel Simulations of Diffusion in Dense Polymeric Structures, Proceedings of the 1997 ACM/IEEE conference on Supercomputing, San Jose, CA, San Jose, CA, 1997.

53. Crank, J., The Mathematics of Diffusion Oxford University Press 1975.

54. World Weather \& Climate Information https://weather-and-climate.com (July 10, 2017).

55. Quéré, D., Fluid Coating on a Fiber Annu. Rev. Fluid Mech. 1999, 31, 347-384.

56. Brinker, C. J., Fundamentals of Sol-Gel Dip Coating Thin Solid Films 1991, 201, 97-109.

57. Scriven, L. E., Physics and Application of Dip Coating and Spin Coating Mat. Res. Soc. Symp.Proc 1988, 121, 717-729.

58. Scavuzzo, J. J.; Yan, X.; Zhao, Y.; Scherger, J. D.; Chen, J.; Zhang, S.; Liu, H.; Gao, M.; Li, T.; Zhao, X.; Hamed, G. R.; Foster, M. D.; Jia, L., Supramolecular Elastomers. Particulate $\beta$ -Sheet Nanocrystal-Reinforced Synthetic Elastic Networks Macromolecules 2016, 49, 26882697.

59. Liu, Q.; Nian, G.; Suo, Z., Bonding Soft Elastomer-Hydrogel Composite for any Fabrication Procedure Unpublished 2017.

60. Morgan, C. R.; Magnotta, F.; Ketley, A. D., Thiol-ene Photocurable Polymers J. Polym. Sci. 1977, 15, 627-645.

61. Sen, A. K.; Mukherjee, B.; Bhattacharyya, A. S.; De, P.; Bhowmick, A. K., Kinetics of Silane Grafting and Moisture Crosslinking of Polyethylene and Ethylene Propylene Rubber $J$. Polym. Sci. 192, 44, 1153-1164. 
62. Geise, G. M.; Paul, D. R.; Freeman, B. D., Fundamental Water and Salt Transport Properties of Polymeric Materials Prog. Polym. Sci. 2014, 39, 1-42.

63. Singh, R. P., Introduction to food engineering 4 ed.; Elsevier 2009.

Table of Contents Only
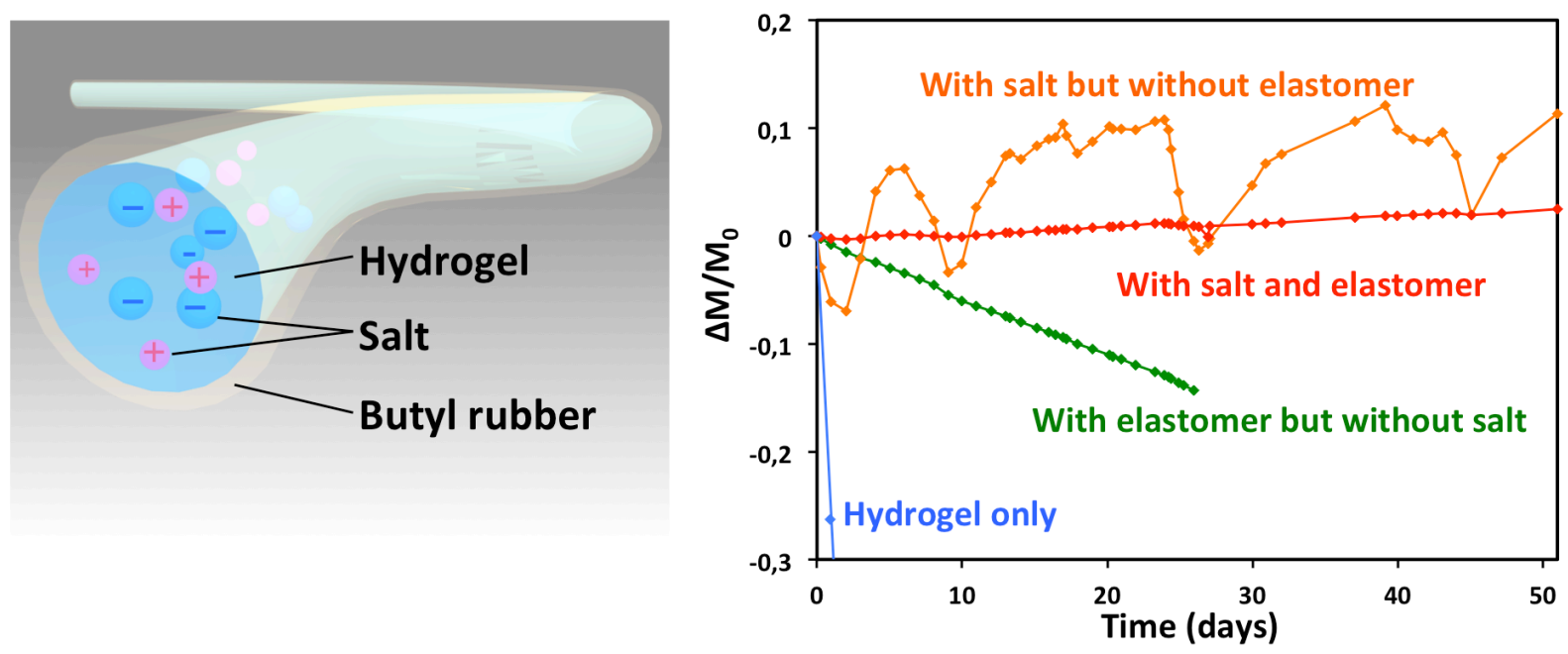